\title{
Clinical and microbiological characteristics of bloodstream infections due to AmpC $\beta$-lactamase producing Enterobacteriaceae: an active surveillance cohort in a large centralized Canadian region
}

\author{
Vikas P Chaubey ${ }^{1,2,8^{*}}$, Johann D D Pitout ${ }^{3,4,5}$, Bruce Dalton ${ }^{2,7}$, Daniel B Gregson ${ }^{2,3,5}$, Terry Ross ${ }^{5}$
} and Kevin B Laupland ${ }^{1,2,3,6}$

\begin{abstract}
Background: The objective of this study was to describe the clinical and microbiological characteristics of bloodstream infections (BSIs) due to AmpC producing Enterobacteriaceae (AE) in a large centralized Canadian region over a 9-year period.

Methods: An active surveillance cohort design in Calgary, Canada.

Results: A cohort of 458 episodes of BSIs caused by AE was assembled for analysis. The majority of infections were of nosocomial origin with unknown sources. Enterobacter spp. was the most common species while BSIs due to Serratia spp. had a significant higher mortality when compared to other AE. Delays in empiric or definitive antibiotic therapy were not associated with a difference in outcome. However, patients that did not receive any empiric antimicrobial therapy had increased mortality $(3 / 5 ; 60 \%$ vs. $57 / 453 ; 13 \% ; p=0.018)$ as did those that did not receive definitive therapy $(6 / 17 ; 35 \%$ vs. $54 / 441 ; 12 \% ; p=0.015)$.

Conclusions: Delays in therapy were not associated with adverse outcomes although lack of active therapy was associated with increased mortality. A strategy for BSIs due to AE where $\beta$-lactam antibiotics (including oxyiminocephalosporins) are used initially followed by a switch to non- $\beta$-lactam antibiotics once susceptibility results are available is effective.
\end{abstract}

Keywords: Beta-lactamases, Bacteremia, Enterobacteriaceae

\section{Background}

Enterobacteriaceae with inducible cephalosporinases such as Enterobacter cloacae, Citrobacter freundii, Serratia marcescens, Morganella morganii, and Providencia stuartii, may become resistant to oxyimino-cephalosporins (i.e. cefotaxime, ceftazidime), 7- $\alpha$-methoxy-cephalosporins (i.e. cephamycins such as cefoxitin) and monobactams by

\footnotetext{
* Correspondence: vikas.chaubey@albertahealthservices.ca

'Department of Community Health Sciences, University of Calgary, TRW Building 3rd Floor, 3280 Hospital Drive NW, Calgary, AB T2N 4Z6, Canada ${ }^{2}$ Department of Medicine, Administration Office, Foothills Medical Centre North Tower, University of Calgary, 9th Floor, 1403 - 29th Street NW, Calgary, AB T2N 2T9, Canada

Full list of author information is available at the end of the article
}

overproducing their chromosomal AmpC $\beta$-lactamases [1]. In Klebsiella pneumoniae, Salmonella spp., and Proteus mirabilis, that lack chromosomal $\beta$-lactamases, this type of resistance can be mediated by plasmid encoded or imported AmpC cephalosporinases [2]. Escherichia coli possesses genes encoding for chromosomal noninducible AmpC $\beta$-lactamases that are regulated by weak promoters and strong attenuators resulting in low amounts of the cephalosporinase [3]. Occasionally, cephamycin-resistant E. coli can also carry plasmidmediated AmpC $\beta$-lactamases [2].

There is controversy about the optimal antibiotic therapy for severe infections caused by AmpC producing 
Enterobacteriaceae (AE), particularly with regards to those that are chromosomally mediated because of the potential for inducibility and selection of derepressed mutants [4-7]. Clinical and Laboratory Standards Institute (CLSI) recommends reporting $\beta$-lactam susceptibilities of these organisms, with a footnote suggesting that resistance may develop during therapy [8]. Literature has shown the importance of early appropriate antibiotic therapy for severe infections in preventing mortality, [9] but few studies have looked at serious infections caused by AE especially those with chromosomal enzymes. Cephalosporin resistant Enterobacteriaceae have been isolated from patients that have previously received broad-spectrum cephalosporins, [10-12] and emergence of cephalosporin resistance has been described during therapy with $\beta$ lactams $[13,14]$. These studies have focused on a single species of AE, [10-12,14] or have included a limited range of organisms [13]. In addition, these studies have included various types of infections and have not clearly demonstrated that therapy with $\beta$-lactams is associated with an increase in mortality.

The objective of this study is to describe the clinical and microbiological characteristics of bloodstream infections (BSIs) due to $\mathrm{AE}$ in a large centralized Canadian region over a 9-year period (2000-08). We also investigate the effects of various empiric and definitive antimicrobial treatment regimens on the mortality of patients with BSIs due to AE. Specifically, we look to determine if definitive treatment with $\beta$-lactam antibiotics are associated with increased mortality in infections caused by AE.

\section{Methods}

\section{Study population}

The Calgary Zone of Alberta Health Services (previously known as the Calgary Health Region) administers virtually all medical and surgical care to the residents of the cities of Calgary and Airdrie and a large surrounding area (population 1.2 million) in the province of Alberta, Canada. All patients with BSIs caused by AE from January 1, 2000 to December $31^{\text {st }}, 2008$ in the Calgary Zone were included in the study. The Conjoint Health Research Ethics Board at the University of Calgary approved this study and granted a waiver of individual patient consent.

We excluded episodes with incomplete data, polymicrobial episodes and those in which the patients died within 24 hours (which may have precluded their receiving appropriate therapy). To investigate the effects of various empiric and definitive antimicrobial treatment regimens on the mortality of patients, patients were divided into two groups. Group I included patients that received definitive therapy with $\beta$-lactams that are hydrolyzed by $\mathrm{AmpC} \beta$-lactamases (i.e. piperacillin-tazobactam), oxyimino-cephalosporins (i.e. cefotaxime, ceftriaxone, ceftazidime) and monobactams (i.e. aztreonam). Group
II included patients that received definitive therapy with non- $\beta$-lactams and/or $\beta$-lactams with sufficient activity in spite of AmpC $\beta$-lactamases (i.e. cefepime and carbapenems).

\section{Study protocol}

An active surveillance cohort design was utilized. Surveillance for $\mathrm{AE}$ were identified using the Electronic Surveillance System at Calgary Laboratory Services [15]. International Statistical Classification of Disease and Health Related Problems (ICD) codes were translated into Charlson Comorbidity Scores using standardized algorithms [16,17]. Antimicrobial therapies were determined using a regional pharmacy database. AE BSIs were defined by the isolation of such bacteria from at least one set of aseptically obtained blood cultures. Repeat isolation from blood from the same patient within 365 days was considered to be the same incident infection.

\section{Definitions}

Empiric therapy was defined as that therapy initiated prior to the availability of blood culture results and sensitivities. Time to first therapy was defined as the time from blood culture draw to receipt of the first dose of antibiotics. Adequate therapy was defined by the receipt of a standard parenteral dose of an antimicrobial to which the organism was susceptible in vitro or a standard oral dose of an antimicrobial with sufficient bioavailability, to which the organism was susceptible in vitro. If the patient received two drugs from different classes to which the bacterium tested susceptible to one agent but resistant to the other agent, the therapy was considered to be adequate. Adequacy of combination antibiotic therapy required the microorganism to be susceptible to all drugs in the combination. Definitive therapy was defined as the final antibiotic chosen to complete a treatment course after the availability of antimicrobial susceptibilities. If the patient was given adequate antibiotics before or at the time of acquiring the blood culture, the time to first adequate therapy was recorded as zero hours. Mortality was defined as the 30-day mortality of patients as determined by searching provincial databases. Definitions of nosocomial, healthcare associated and community-acquired infections used in this study, have previously been described [18].

\section{Laboratory methods}

Clinical isolates were identified and minimum inhibitory concentrations (MICs) were determined by Vitek $2^{\text {ma }}$ (Vitek AMS; bioMérieux Vitek Systems Inc., Hazelwood, MO). Susceptibility testing and reporting was performed according to the CLSI guidelines for broth dilution [8]. Enterobacteriaceae potentially possessing chromosomally mediated AmpC $\beta$-lactamases did not undergo 
confirmatory testing for the AmpC gene and/or inducibility of these genes.

These included: Citrobacter spp. (C. braakii, C. freundii, C. youngae), Enterobacter spp. (E. aerogenes, E. asburiae, E. cancerogenus, E. cloacae, E. sakazakii), Hafnia alvei, Morganella morganii, Providencia spp. (P. rettgeri, P. stuartii) and Serratia spp. (S. liquefaciens, S. marcescens, S. odorfera) [5].

After isolates were first shown to be non-susceptible to cefoxitin, the presence of AmpC $\beta$-lactamases in E. coli, $K$. pneumoniae and Salmonella isolates was confirmed using previously described boronic acid methodology [19].

The policy of the centralized microbiology laboratory is to suppress the susceptibility results of all $\beta$-lactam antibiotics for potential AE. Only fluoroquinolones, aminoglycosides and trimethoprim/sulfamethoxazole are routinely reported for infections caused by potential AE. Cefepime and carbapenem susceptibilities are available upon request.

\section{Statistical analysis}

Analysis was performed using Stata version 10.0 (Stata Corp, College Station, TX). Non-normally distributed data were described using medians with interquartile ranges (IQR). Categorical data were compared using the two-sided Fisher's exact test. P-values less than 0.05 were considered significant. Logistic regression models were developed to assess the independent effects of various factors on mortality. Treatment adequacy and timing, and all factors found to be significant to the $\mathrm{P}<0.1$ level in univariate analyses were included in the initial models. Backward stepwise variable elimination was then performed to develop the most parsimonious model. Discrimination was assessed using the area under the receiver operator characteristic (ROC) curve and calibration using the Hosmer-Lemeshow goodness-of-fit test.

\section{Results}

\section{Study population}

Five hundred and ninety incident episodes of AE BSIs were identified between 2000 and 2008. After excluding patients with incomplete data $(n=64)$, polymicrobial infection $(n=54,9)$ or that died within 24 hours of culture draw $(n=14)$ a cohort of $458(78 \%)$ episodes remained for further analysis.

\section{Clinical characteristics (see Table 1 for further details)}

The median patient age was 62.5 years (IQR, 43.675.6 years), 283 (62\%) were male, and the median ageadjusted Charlson score was 4 (IQR, 4-11). The majority of infections were nosocomially-acquired ( $n=232,51 \%)$ and patients most often presented with primary BSIs $(\mathrm{n}=$ 224, 50\%). The most common comorbid condition was malignancy $(\mathrm{n}=81,18 \%)$. BSIs due to AE remained stable over the time period; however we did notice a slight increase in 2008.

\section{Microbiological characteristics (see Table 1 for further details)}

Enterobacter $(\mathrm{n}=225,49 \%)$, Serratia $(\mathrm{n}=73,16 \%)$ and Citrobacter $(\mathrm{n}=51,11 \%)$ species were the most common bacteria responsible for BSIs due to AE. Ciprofloxacin, gentamicin, tobramycin, cefepime and imipenem showed excellent activity against various $\mathrm{AE}$ (excluding $E$. coli) with susceptibility ranging from $89 \%-100 \%$. E. coli with AmpC $\beta$-lactamases showed the highest levels of resistance to ciprofloxacin (20\%), gentamicin (23\%), and tobramycin (13\%). Excluding primary BSIs, there was a strong association of Enterobacter spp. with the presence of underlying BTIs $(46 / 255,18 \%)$ while the isolation of Citrobacter and Providencia/Morganella spp were associated with underlying UTIs.

\section{Outcomes (see Table 2 for further details)}

Overall $60(13 \%)$ patients died within thirty days. $S$. marcescens had the highest mortality $(15 / 52 ; 29 \%)$ and Citrobacter spp. had the lowest mortality $(1 / 51 ; 2.0 \%)$.

\section{Description of therapy (see Tables 2 and 3 for further details)}

Empiric therapy was provided in 453 (99\%) cases. The most common agents used as empiric therapy included piperacillin-tazobactam $(131,29 \%)$ and oxyiminocephalosporins $(106,23 \%)$. Empiric therapy was started immediately in $172(38 \%)$ patients, within 8 hours in 277 (60\%) patients, within 24 hours in 391 (85\%) patients and within 48 hours in 427 (93\%) patients. The timing of empiric antibiotic therapy was not associated with a difference in outcome. However, patients that did not receive empiric antimicrobial therapy had a worse outcome $(3 / 5$; $60 \%$ vs. $57 / 453 ; 13 \% ; \mathrm{p}=0.018$ ). The number, combination (at least two antibiotics from different classes), or class of antibiotic was also not associated with any statistically significant improvement in outcome (data not shown). Empiric therapy with piperacillin-tazobactam or an oxyimino-cephalosporin was not associated with a difference in mortality outcome $(28 / 237 ; 12 \%$ vs. $32 / 221 ; 14 \%$; $\mathrm{p}=0.41$ ). Of 131 that received empiric piperacillintazobactam, the case-fatality rate was $2 / 19$ (11\%) for those patients with isolates that tested resistant at baseline as compared to $13 / 112$ (12\%) for those isolates that tested sensitive, $\mathrm{p}=0.89$. Notably, of 106 patients who received oxyimino-cephalosporins as empiric therapy, the case-fatality rate was 5/18 (28\%) for those patients with isolates that tested resistant at baseline as compared to $8 / 88(9 \%)$ for those that were sensitive, $\mathrm{p}=0.04$.

Adequate therapy was provided in 441 (96\%) cases. The most common agents used as adequate therapy included 
Table 1 Clinical and microbiological characteristics of bloodstream infections due to AmpC-producing Enterobacteriaceae in the Calgary Zone

\begin{tabular}{|c|c|c|c|c|c|c|}
\hline & Enterobacter spp. ${ }^{1}$ & Serratia spp. $^{2}$ & Citrobacter spp. ${ }^{3}$ & $\begin{array}{l}\text { Providencia \& } \\
\text { Morganella spp. }\end{array}$ & E. coli ${ }^{5}$ & Other $^{6}$ \\
\hline No. of episodes & 255 & 73 & 51 & 39 & 30 & 10 \\
\hline \multicolumn{7}{|l|}{ Source of infection (no. episodes) } \\
\hline Biliary & 46 & 2 & 6 & 2 & 3 & 4 \\
\hline Bowel & 18 & 5 & 4 & 4 & 2 & 0 \\
\hline Urinary & 43 & 10 & 13 & 15 & 5 & 2 \\
\hline Pneumonia & 14 & 13 & 2 & 0 & 1 & 0 \\
\hline CVS source & 0 & 1 & 0 & 0 & 0 & 0 \\
\hline SST source & 7 & 4 & 0 & 0 & 0 & 0 \\
\hline BJ source & 1 & 0 & 2 & 4 & 0 & 0 \\
\hline CNS source & 1 & 0 & 0 & 0 & 0 & 0 \\
\hline Unknown & 125 & 38 & 24 & 14 & 19 & 4 \\
\hline \multicolumn{7}{|l|}{ Comorbid conditions } \\
\hline Myocardial infarction & 15 (5.9\%) & $4(5.5 \%)$ & $4(7.8 \%)$ & $4(10 \%)$ & $2(6.7 \%)$ & $0(0 \%)$ \\
\hline $\mathrm{CHF}$ & $32(13 \%)$ & $18(25 \%)$ & $5(9.8 \%)$ & $6(15 \%)$ & $2(6.7 \%)$ & $1(10 \%)$ \\
\hline PVD & $6(2.4 \%)$ & 7 (9.6\%) & $1(2.0 \%)$ & $4(10 \%)$ & $2(6.7 \%)$ & $1(10 \%)$ \\
\hline CVD & $8(3.1 \%)$ & $5(6.8 \%)$ & $1(2.0 \%)$ & $2(5.1 \%)$ & $0(0 \%)$ & $1(10 \%)$ \\
\hline Dementia & $2(<1 \%)$ & $0(0 \%)$ & $2(3.9 \%)$ & $3(8.5 \%)$ & $1(3.3 \%)$ & $0(0 \%)$ \\
\hline CPD & $20(7.8 \%)$ & $13(18 \%)$ & $2(3.9 \%)$ & $5(13 \%)$ & $8(27 \%)$ & $3(30 \%)$ \\
\hline Rheumatic disease & $2(<1 \%)$ & $0(0 \%)$ & $1(2.0 \%)$ & $3(8.5 \%)$ & $0(0 \%)$ & $0(0 \%)$ \\
\hline Peptic ulcer disease & $9(3.5 \%)$ & $4(5.5 \%)$ & $1(2.0 \%)$ & $2(5.1 \%)$ & $0(0 \%)$ & $1(10 \%)$ \\
\hline Hemiplegia/Paraplegia & $6(2.4 \%)$ & $4(5.5 \%)$ & $2(3.9 \%)$ & $3(8.5 \%)$ & $1(3.3 \%)$ & $0(0 \%)$ \\
\hline Renal disease & $31(12 \%)$ & 17 (23\%) & $7(14 \%)$ & $9(23 \%)$ & $2(6.7 \%)$ & $0(0 \%)$ \\
\hline Mild liver disease & 10 (3.9\%) & $1(1.4 \%)$ & $1(2.0 \%)$ & $0(0 \%)$ & $0(0 \%)$ & $0(0 \%)$ \\
\hline Moderate severe liver disease & $12(4.7 \%)$ & $4(5.5 \%)$ & $1(2.0 \%)$ & $2(5.1 \%)$ & $2(6.7 \%)$ & $1(10 \%)$ \\
\hline Malignancy & $53(21 \%)$ & $8(11 \%)$ & $15(29 \%)$ & $2(5.1 \%)$ & $1(3.3 \%)$ & $2(20 \%)$ \\
\hline Metastatic solid cancer & $27(11 \%)$ & $3(4.1 \%)$ & $2(3.9 \%)$ & $1(2.6 \%)$ & $5(17 \%)$ & $1(10 \%)$ \\
\hline DM w/o complication & $25(9.8 \%)$ & $7(9.6 \%)$ & $2(3.9 \%)$ & $4(10 \%)$ & $3(10 \%)$ & $0(0 \%)$ \\
\hline DM w/ complications & $14(5.5 \%)$ & $6(8.2 \%)$ & $3(5.9 \%)$ & $6(15 \%)$ & $1(3.3 \%)$ & $0(0 \%)$ \\
\hline Median Charlson (IQR) & $3(1-5)$ & $4(2-6)$ & $3(2-4)$ & $4(3-7)$ & $4(1-5)$ & $4(4-6)$ \\
\hline Median age (IQR) & $58.0(39-72.3)$ & $65.6(52.1-74.2)$ & $59.1(36.6-75.3)$ & $72.9(62.9-79.6)$ & $58.6(41.1-77.3)$ & $71.2(64.4-81.6)$ \\
\hline Male sex (\%) & $62 \%$ & $60 \%$ & $75 \%$ & $74 \%$ & $33 \%$ & $50 \%$ \\
\hline \multicolumn{7}{|l|}{ Surveillance definition } \\
\hline Nosocomial & $138(24,17 \%)$ & $45(14,31 \%)$ & $22(1,4.5 \%)$ & $13(2,15 \%)$ & $11(0,0 \%)$ & $3(0,0 \%)$ \\
\hline $\mathrm{HCAl}$ & $70(6,8.6 \%)$ & $12(1,8.3 \%)$ & $16(0,0 \%)$ & $17(3,18 \%)$ & $10(1,10 \%)$ & $4(0,0 \%)$ \\
\hline Community acquired & $47(3,6.4 \%)$ & $16(3,19 \%)$ & $13(0,0 \%)$ & $9(1,11 \%)$ & $9(0,0 \%)$ & $3(1,33 \%)$ \\
\hline$p$-value & 0.08 & 0.248 & 1.000 & 1.000 & 0.633 & 0.600 \\
\hline \multicolumn{7}{|l|}{ Per year of infection } \\
\hline 2000 & $20(7.8 \%)$ & $6(8.2 \%)$ & $2(3.9 \%)$ & $7(18 \%)$ & $0(0 \%)$ & $1(10 \%)$ \\
\hline 2001 & $26(10 \%)$ & $13(18 \%)$ & $3(5.9 \%)$ & $0(0 \%)$ & $4(13 \%)$ & $3(30 \%)$ \\
\hline 2002 & $24(9.4 \%)$ & $5(6.9 \%)$ & $5(9.8 \%)$ & $1(2.6 \%)$ & $4(13 \%)$ & $1(10 \%)$ \\
\hline 2003 & $33(13 \%)$ & $3(4.1 \%)$ & $3(5.9 \%)$ & $9(23 \%)$ & $5(17 \%)$ & $2(20 \%)$ \\
\hline 2004 & $31(12 \%)$ & $9(12 \%)$ & $8(16 \%)$ & $3(7.7 \%)$ & $2(6.7 \%)$ & $2(20 \%$ \\
\hline 2005 & $20(7.8 \%)$ & $14(19 \%)$ & $8(16 \%)$ & $8(21 \%)$ & $2(6.7 \%)$ & $1(10 \%)$ \\
\hline
\end{tabular}


Table 1 Clinical and microbiological characteristics of bloodstream infections due to AmpC-producing Enterobacteriaceae in the Calgary Zone (Continued)

\begin{tabular}{|c|c|c|c|c|c|c|}
\hline 2006 & $24(9.4 \%)$ & $6(8.2 \%)$ & $5(9.8 \%)$ & $5(13 \%)$ & $7(23 \%)$ & $0(0 \%)$ \\
\hline 2007 & $31(12 \%)$ & $7(9.6 \%)$ & $10(20 \%)$ & $2(5.1 \%)$ & $2(6.7 \%)$ & $0(0 \%)$ \\
\hline 2008 & $46(18 \%)$ & $10(14 \%)$ & $7(14 \%)$ & $4(10 \%)$ & $4(13 \%)$ & $0(0 \%)$ \\
\hline \multicolumn{7}{|l|}{$\begin{array}{l}\text { Susceptibility testing } \\
\text { (percentage susceptible) }\end{array}$} \\
\hline Ciprofloxacin & 248/255 (98\%) & 71/73 (97\%) & $47 / 50(94 \%)$ & $36 / 38(95 \%)$ & $24 / 30(80 \%)$ & $10 / 10(100 \%$ \\
\hline Gentamicin & 251/255 (99\%) & 72/73 (99\%) & $45 / 50(90 \%)$ & $34 / 38(90 \%)$ & 23/30 (77\%) & $10 / 10(100 \%$ \\
\hline Piperacillin-tazobactam & $203 / 255(80 \%)$ & 69/73 (95\%) & $46 / 50(92 \%)$ & $38 / 38(100 \%)$ & 29/30 (97\%) & $7 / 10$ (70\%) \\
\hline TMP/SMX & $242 / 255(95 \%)$ & 73/73 (100\%) & $39 / 50(78 \%)$ & $31 / 38(82 \%)$ & 19/30 (63\%) & $10 / 10(100 \%$ \\
\hline Tobramycin & 251/255 (99\%) & 64/73 (88\%) & $45 / 50(90 \%)$ & $33 / 38(87 \%)$ & 26/30 (87\%) & $10 / 10(100 \%$ \\
\hline Imipenem & $255 / 255(100 \%)$ & 73/73 (100\%) & $50 / 50(100 \%)$ & $38 / 38(100 \%)$ & $30 / 30(100 \%)$ & $10 / 10(100 \%)$ \\
\hline
\end{tabular}

${ }^{1}$ Includes 34 E. aerogenes, 1 E. asburiae, 2 E. cancerogenus, 210 E. cloacae, 6 E. sakazakii and 2 E. spp bacteremia episodes.

${ }^{2}$ Includes 3 S. liquefaciens, 67 S. marcescens, 1 S. odorfera and 2 S. spp. bacteremia episodes.

${ }^{3}$ Includes 17 C. braakii, 30 C. freundii, 2 C. spp. and 2 C. youngae bacteremia episodes.

${ }^{4}$ Includes 27 M. Morganii, 3 P. rettgeri and 9 P. stuartii bacteremia episodes.

${ }^{5}$ Includes $30 \mathrm{E}$. coli bacteremia episodes.

${ }^{6}$ Includes $7 \mathrm{H}$. alveii, 2 Salmonella spp. and $1 \mathrm{~K}$. pneumoniae bacteremia episodes.

CVS $=$ Cardiovascular, SST $=$ Skin and Soft Tissue, $\mathrm{BJ}=$ Bone and Joint, $\mathrm{CNS}=$ Central Nervous System, CHF = Congestive Heart Failure, PVD $=$ Peripheral Vascular

Disease, $C V D=$ Cerebrovascular Disease, $C P D=$ Chronic Pulmonary Disease, $T M P / S M X=$ Trimethoprim/Sulfamethoxazole.

piperacillin-tazobactam $(133,29 \%)$ and oxyiminocephalosporins $(106,23 \%)$. Adequate therapy was received immediately in 98 (21\%) patients, within 8 hours in $194(42 \%)$ patients, within 24 hours in 327 (71\%) patients and within 48 hours in 389 (85\%) patients. Early receipt of adequate antibiotic therapy was not associated with improved outcomes. Adequate number, combination (at least two antibiotics from different classes to which the microorganism had in vitro susceptibility) or class of antibiotic was not associated with improved outcome (data not shown). First adequate therapy with piperacillintazobactam or an oxyimino-cephalosporin was not associated with different outcomes $(28 / 241 ; 12 \%$ vs. $32 / 217$; $15 \% ; \mathrm{p}=0.33$ ). Patients that did not receive any form of definitive therapy did have a worse outcome $(6 / 17 ; 35 \%$ vs. $54 / 441 ; 12 \% ; \mathrm{p}=0.015)$. The analysis that assessed the outcomes of patients in groups I and II did not reveal a mortality difference (Group I: 4/22; $18 \%$ vs. Group II: $50 /$ $419 ; 12 \%, \mathrm{p}=0.33$ ) or a differences in relapse of infection with the same bacteria (Group I: $3 / 22 ; 14 \%$ vs. Group II: $27 / 419,6.4 \%, \mathrm{p}=0.182$ ).

Logistic regression model (see Table 4 for further details)

A logistic regression model was developed to assess the effect of timing and adequacy of therapy $(n=458)$ and had good calibration (Hosmer-Lemeshow goodness of fit $\mathrm{p}=0.49$ and discrimination (area under $\mathrm{ROC}=$ 0.808 ; ROC curve not shown). Early adequate therapy between 8-24 hours after blood culture draw had worse outcomes (Odds Ratio (OR) 2.01, p =0.050) while delayed therapy at $\mathrm{T}>24$ hours to $\mathrm{T}=48$ hours had increased survival that did not reach statistical significance
(OR 0.44, $\mathrm{p}=0.70$ ). Never having received definitive therapy demonstrated an increased risk of death (OR $4.78, \mathrm{p}=0.013)$.

\section{Discussion}

Our study described the clinical and microbiological characteristics of BSIs due to AE over a 9-year period. The majority of infections were of nosocomial origin with unknown sources. Patients often had underlying malignancy and the highest rates of mortality were associated with underlying pneumonia. Enterobacter spp. was by far the most common bacteria responsible for BSIs due to $\mathrm{AE}$ and was associated with underlying BTIs. Interestingly, we found that BSIs due to Serratia spp. had a significant higher mortality when compared to other AE.

As demonstrated in our study, previous studies of $\mathrm{AE}$ BSIs have consistently shown Enterobacter spp. as the most common microbiologic etiology, [20-23] and malignancy as the most common underlying condition [10,21-29]. The most common sources of AE BSIs from the literature include unknown source, biliary source and urinary source (variably ranked), in studies including either a single species or multiple species of $\mathrm{AE}$ [10,23-27]. Our study is unique in that the mortality of Serratia spp. BSIs is particularly high relative to what others have found [21].

Early and adequate antimicrobial therapy is a cornerstone of treatment of severe infections including BSIs. Several studies have found a clear relationship between time to first adequate therapy and mortality [9,30-32]. Most of these studies utilize in vitro susceptibility to establish adequacy of therapy and this may not be appropriate 
Table 2 Factors investigated for association with 30-day case fatality (univariate analysis)

\begin{tabular}{ll}
\hline Factor & Case fatality \\
\hline Male & $42 / 283(15 \%)$ \\
*Age-adjusted Charlson > median (4) & $48 / 230(21 \%)$ \\
Source of bacteremia & \\
Unknown & $26 / 224(12 \%)$ \\
Urinary & $6 / 88(6.8 \%)$ \\
Biliary & $4 / 63(6.3 \%)$ \\
Bowel & $7 / 33(21.1 \%)$ \\
Pneumonia & $12 / 30(40 \%)$ \\
Skin and soft tissue infection & $3 / 11(28 \%)$ \\
Bone and joint & $2 / 7(29 \%)$ \\
CNS & $0 / 1(0 \%)$ \\
CVS & $0 / 1(0 \%)$
\end{tabular}

Nosocomial

Healthcare associated

Community-acquired

Microbiology**

Enterobacter spp.

$$
\begin{aligned}
& \text { E. aerogenes } \\
& \text { E. asburiae } \\
& \text { E. cancerogenus } \\
& \text { E. cloacae } \\
& \text { E. sakazakii } \\
& \text { E. spp. }
\end{aligned}
$$

Serratia spp.

S. liquefaciens

S. marcescens

S. odorfera

S. spp.

Citrobacter spp. ${ }^{* *}$

C. braakii

C. freundii

C. spp.

C. youngae

Escherichia coli

Morganella morganii

Providencia spp.

$$
\text { P. rettgeri }
$$

P. stuartii

Hafnei alvei

Salmonella spp.

Klebsiella pneumoniae

Plasmid mediated
41/232 (17.7\%)

$11 / 129(8.5 \%)$

$8 / 97(8.2 \%)$
P-value

0.20

$<0.001$

0.001

$5 / 34(15 \%)$

0/1 (0\%)

$0 / 2(0 \%)$

26/210 (13\%)

$2 / 6(33 \%)$

$0 / 2(0 \%)$

18/73 (25\%)

$2 / 3(66 \%)$

15/67 (22\%)

$1 / 1(100 \%)$

$0 / 2(0 \%)$

1/51 (2.0\%)

$0 / 17(0 \%)$

$1 / 30(3.3 \%)$

$0 / 2(0 \%)$

$0 / 2(0 \%)$

$1 / 30(3.3 \%)$

$4 / 27$ (15\%)

2/12 (17\%)

$1 / 3(33 \%)$

$1 / 9(11 \%)$

$1 / 7$ (14\%)

$0 / 2(0 \%)$

$0 / 1(0 \%)$

1/33 (3.0\%) 
Table 2 Factors investigated for association with 30-day case fatality (univariate analysis) (Continued)

\begin{tabular}{ll}
\hline Description of empiric therapy & \\
Empiric therapy in hours at: & $23 / 172(13 \%)$ \\
$t=0$ & $11 / 105(10 \%)$ \\
$t>0$ and $t=8$ & $17 / 114(15 \%)$ \\
$t>8$ and $t=24$ & $3 / 36(8.3 \%)$ \\
$t>24$ and $t=48$ & $3 / 26(12 \%)$ \\
Empiric at $t>48$ hrs. & $3 / 5(60 \%)$ \\
Never received empiric therapy. & \\
Description of adequate therapy & $11 / 98(11 \%)$ \\
Adequate therapy in hours at: & $11 / 96(11 \%)$ \\
$t=0$ hrs. & $23 / 133(17 \%)$ \\
$t>0$ and $t=8$ & $5 / 62(8.1 \%)$ \\
$t>8$ and $t=24$ & $4 / 52(7.7 \%)$ \\
$t>24$ and $t=48$ & $6 / 17(35 \%)$ \\
$t>48$ hrs. & \\
Never received adequate or definitive therapy. & \\
\hline CNS: Central Nervous System. CvS: Cardiovascular System. $95 \%$ Cl: $95 \%$ Confidence Interval. \\
*Charlson data was missing for 11 patients; their Charlson score was assumed to be zero and then adjusted for age. \\
**Some isolates were not speciated beyond the genus level.
\end{tabular}
**Some isolates were not speciated beyond the genus level.

in the specific case of AE organisms. Our study revealed that delays in active antibiotic therapy were not associated with a poor outcome. However, patients that did not receive any empiric or definitive antimicrobial therapy had increased mortality. While the importance of appropriate early antimicrobial therapy is generally accepted, there are several studies that do not support this premise [33-37]. Our patient population was not limited to the critically ill and this may explain why we were not able to demonstrate an association between early adequate antimicrobial therapy and increased survival.

Previous studies have investigated the issue of resistance development during treatment with oxyiminocephalosporins of infections due to AE. A previous study had shown a low risk of emergence of resistance during therapy and a low risk of associated mortality [13]. However that study included only a select number of $\mathrm{AE}$ and included a broad range of infections types. Another study showed that after treatment, 477 patients with susceptible Enterobacter spp. infections, 49 (10.3\%) subsequently developed cephalosporin resistant isolates [11]. This study did not specifically address mortality. The policy of the centralized laboratory to suppress susceptibilities for all $\beta$-lactam antibiotics for infections caused by $\mathrm{AE}$ resulted in clinicians changing the definitive antimicrobial therapy to non- $\beta$-lactam antibiotics once susceptibility results were available. After excluding all patients that died early and that did not receive definitive therapy only 22 of 441 patients completed definitive therapy with oxyimino-cephalosporins. The low numbers of patients treated with oxyimino-cephalosporins thus precluded us from determining the efficacy of this regimen. Our study did however reveal that patients empirically treated with oxyimino-cephalosporins, when the isolate was resistant at baseline, had a statistically worse outcome. This supports the notion that initial empiric therapy with oxyimino-cephalosporins may be effective for $\mathrm{AE}$ that test in vitro sensitive to these agents. We recommend that patients who previously received oxyimino-cephalosporins should be treated empirically with an alternate class of agent because of the risk of being colonized with oxyimino-cephalosporin resistant AE.

In the multivariate model it was noted that adequate therapy at between 8-24 hours after blood culture draw had worse outcomes while delayed adequate therapy at $\mathrm{T}>24$ hours to $\mathrm{T}=48$ hours had increased survival; findings that did not reach statistical significance. Our group has previously reported similar results [34]. This interesting finding was most likely the result of sicker patients receiving broader and more prompt empiric antimicrobials as a result of their clinical condition. Again, our study is limited in that we did not collect data regarding severity of illness. Furthermore, since these findings did not reach statistical significance they may have occurred by chance alone. It should be mentioned that the numbers of patients that did not receive empiric or definitive therapy were small, 5 and 17 respectfully. As such, any specific conclusions could not be generated.

There are several limitations of our study mostly arising from our pharmacy database. This database did not capture all outpatient data. It is conceivable that the 22 
Table 3 *Empiric, first adequate and definitive antimicrobial choice and associated 30-day case-fatality

\begin{tabular}{|c|c|c|c|c|c|}
\hline Empiric antibiotic choice & $\begin{array}{l}\text { Case } \\
\text { fatality rate }\end{array}$ & $\begin{array}{l}\text { First adequate antibiotic } \\
\text { choice }\end{array}$ & $\begin{array}{l}\text { Case } \\
\text { fatality rate }\end{array}$ & $\begin{array}{l}\text { Definitive antimicrobial } \\
\text { therapy }\end{array}$ & $\begin{array}{l}\text { Case } \\
\text { fatality rate }\end{array}$ \\
\hline \multicolumn{6}{|l|}{$\begin{array}{l}\text { Antibiotics with activity against AmpC- } \\
\text { producing Enterobacteriaceae }\end{array}$} \\
\hline Aminoglycoside & $7 / 52(13 \%)$ & Aminoglycoside & $10 / 80(13 \%)$ & Aminoglycoside & 15/132 11\%) \\
\hline $\begin{array}{l}\text { Beta-lactam/Beta-lactamase inhibitor } \\
\text { combination }\end{array}$ & $\begin{array}{l}15 / 131 \\
(11 \%)\end{array}$ & $\begin{array}{l}\text { Beta-lactam/Beta-lactamase } \\
\text { inhibitor combination }\end{array}$ & $\begin{array}{l}16 / 137 \\
(12 \%)\end{array}$ & $\begin{array}{l}\text { Beta-lactam/Beta-lactamase } \\
\text { inhibitor combination }\end{array}$ & $10 / 22(45 \%)$ \\
\hline Carbapenem & 0/16 (0\%) & Carbapenem & $3 / 31(9.7 \%)$ & Carbapenem & $5 / 45(11 \%)$ \\
\hline Cefepime & $1 / 3(33 \%)$ & Cefepime & $1 / 5(20 \%)$ & Cefepime & $1 / 4(25 \%)$ \\
\hline Cefoxitin & $0 / 1(0 \%)$ & Cefixime & 0/10 (0\%) & Cefotaxime & $0 / 2(0 \%)$ \\
\hline Ceftazidime & $1 / 15(6.7 \%)$ & Ceftazidime & 0/10 (0\%) & Ceftazidime & 0/1 (0\%) \\
\hline Ceftriaxone & $11 / 85(13 \%)$ & Ceftriaxone & $12 / 97(12 \%)$ & Ceftriaxone & $1 / 7(14 \%)$ \\
\hline Cefuroxime & $1 / 5(20 \%)$ & Colistin & $0 / 1(0 \%)$ & Colistin & $0 / 1(0 \%)$ \\
\hline Colistin & 0/1 (0\%) & Fluoroquinolone & $\begin{array}{l}16 / 106 \\
(15 \%)\end{array}$ & Fluoroquinolone & $\begin{array}{l}30 / 231 \\
(13 \%)\end{array}$ \\
\hline Fluoroquinolone & 10/76 (13\%) & TMP/SMX & $0 / 9(0 \%)$ & TMP/SMX & 0/14 (0\%) \\
\hline TMP/SMX & $2 / 14(14 \%)$ & & & & \\
\hline \multicolumn{6}{|l|}{$\begin{array}{l}\text { Antibiotics unlikely to have activity against } \\
\text { AmpC-producing Enterobacteriaceae }\end{array}$} \\
\hline Ampicillin & $3 / 30(10 \%)$ & & & & \\
\hline Azithromycin & $1 / 5(20 \%)$ & & & & \\
\hline Cefazolin & $5 / 39(13 \%)$ & & & & \\
\hline Cephalexin & $0 / 2(0 \%)$ & & & & \\
\hline Clindamycin & $0 / 4(0 \%)$ & & & & \\
\hline Cloxacillin & 2/7 (29\%) & & & & \\
\hline Linezolid & $0 / 1(0 \%)$ & & & & \\
\hline Metronidazole & $12 / 68(18 \%)$ & & & & \\
\hline Penicillin & $0 / 3(0 \%)$ & & & & \\
\hline Rifampin & $0 / 3(0 \%)$ & & & & \\
\hline Vancomycin & $6 / 37(16 \%)$ & & & & \\
\hline
\end{tabular}

TMP/SMX = Trimethoprim/Sulfamethoxazole.

*For each category the total number of episodes adds up to more than the actual number of episodes because some patients received multiple antibiotics corresponding to each time period.

Table 4 Logistic regression model

\begin{tabular}{|c|c|c|c|}
\hline Variable & Odds ratio & $95 \% \mathrm{Cl}$ & P-value \\
\hline Age adjusted Charlson score (per point) & 1.34 & $1.20-1.49$ & $<0.001$ \\
\hline \multicolumn{4}{|l|}{ Source of infection } \\
\hline \multicolumn{4}{|l|}{ Biliary (reference) } \\
\hline Bowel & 3.87 & $1.27-11.80$ & 0.018 \\
\hline Pneumonia & 12.98 & 4.49-37.46 & $<0.001$ \\
\hline SSTI & 12.64 & $2.35-68.07$ & 0.003 \\
\hline Unknown & 2.24 & $1.04-4.822$ & 0.039 \\
\hline \multicolumn{4}{|l|}{ Treatment group } \\
\hline Adequate therapy at $\mathrm{T}=8-24$ hours. & 2.01 & $1.00-4.03$ & 0.050 \\
\hline Adequate therapy at $\mathrm{T}>24$ hours to $\mathrm{T}=48$ hours. & 0.44 & $0.18-1.07$ & 0.70 \\
\hline Never received definitive therapy. & 4.78 & $1.39-16.44$ & 0.013 \\
\hline
\end{tabular}


(or a proportion thereof) patients that are classified as having completed definitive $\beta$-lactam therapy may have received outpatient definitive non- $\beta$-lactam therapy after initial improvement. In addition, the pharmacy database may have not captured all ward stock antibiotics dispensed and the pharmacy database captured the time the antibiotic was dispensed which may not have correlated with the time the antibiotic was administered. Finally, the cohort assembled for this study included potential AmpC producers, and it is possible that some of the isolates may not have had the AmpC $\beta$-lactamase gene. In the clinical context it is impractical due to time and financial constraints to test each isolate for the presence of the AmpC gene and/or inducibility of these genes. As such our study attempted to answer this question from a feasibility perspective.

\section{Conclusion}

In conclusion, Enterobacter spp. is the most common $\mathrm{AE}$ that causes BSIs in the Calgary region. A strategy where $\beta$-lactam therapy (including oxyimino-cephalosporins) is used as initial therapy for severe infections caused by $\mathrm{AE}$ followed by a switch to non- $\beta$-lactam therapy once susceptibility results are available is effective. The efficacy of using oxyimino-cephalosporins as definitive therapy for severe $\mathrm{AE}$ infections remains unknown.

\section{Abbreviations \\ BSI: Bloodstream infection; AE: AmpC producing Enterobacteriaceae; CLSI: Clinical and Laboratory Standards Institute; ICD: International Statistical Classification of Disease and Health Related Problems; MIC: Minimum Inhibitory Concentrations; IQR: Interquartile ranges; ROC: Receiver operator characteristic; UTI: Urinary Tract Infections; BTI: Biliary Tract Infections; OR: Odds Ratio.}

\section{Competing interests}

All authors declare that they have no competing interests.

\section{Authors' contributions}

All authors contributed to study conception and design. V.P.C., J.D.D.P. and K. B.L. performed the primary data analysis and drafting of the manuscript. J.D. D.P. performed the molecular detection of ampC enzymes. B.D. and T.R. contributed to data collection and database management. All authors critically reviewed and approved the manuscript.

\section{Acknowledgements}

This study was funded by an unrestricted research grant from Merck Frosst Canada Inc. The authors had full autonomy in the design, conduct, reporting, and decision to publish. J.D.D.P. has previously received research funds from Merck Frosst and Astra Zeneca. K.B.L. has received unrestricted research grants and speakers honoraria from Merck Frosst Canada Inc.

\section{Author details}

'Department of Community Health Sciences, University of Calgary, TRW Building 3rd Floor, 3280 Hospital Drive NW, Calgary, AB T2N 4Z6, Canada. ${ }^{2}$ Department of Medicine, Administration Office, Foothills Medical Centre North Tower, University of Calgary, 9th Floor, 1403 - 29th Street NW, Calgary, AB T2N 2T9, Canada. ${ }^{3}$ Department of Pathology and Laboratory Medicine, University of Calgary, Diagnostic \& Scientific Centre 9, 3535 Research Road NW, Calgary, AB T2L 2K8, Canada. ${ }^{4}$ Department of Microbiology, Immunology and Infectious Diseases, Health Research Innovation Centre, University of Calgary, Room 4AA06, 3330 Hospital Drive NW, Calgary, AB T2N 4N1, Canada. ${ }^{5}$ Calgary Laboratory Services, Alberta Health Services,
Diagnostic \& Scientific Centre 9, 3535 Research Road NW, Calgary, AB T2L 2K8, Canada. ${ }^{6}$ Centre for Antimicrobial Resistance, University of Calgary, 3330 Hospital Drive N.W., Calgary, AB T2N 4N1, Canada. ${ }^{7}$ Department of Pharmacy Services, Alberta Health Services, Foothills Medical Centre, Rm 1080, 10th floor, 1403 29th St NW, Calgary, AB T2N 2T8, Canada. ${ }^{8}$ FRCPC, MDCM, TRW Building, 3rd Floor, 3280 Hospital Drive NW, Calgary, AB T2N 4Z6, Canada.

Received: 27 December 2013 Accepted: 21 November 2014

Published online: 14 December 2014

\section{References}

1. Jacoby GA, Munoz-Price LS: The new beta-lactamases. N Engl J Med 2005, 352(4):380-391.

2. Philippon A, Arlet $G$, Jacoby GA: Plasmid-determined AmpC-type beta-lactamases. Antimicrob Agents Chemother 2002, 46(1):1-11.

3. Mulvey MR, Bryce E, Boyd DA, Ofner-Agostini M, Land AM, Simor AE, Paton S: Molecular characterization of cefoxitin-resistant Escherichia coli from Canadian hospitals. Antimicrob Agents Chemother 2005, 49(1):358-365.

4. Goldstein FW: Cephalosporinase induction and cephalosporin resistance: a longstanding misinterpretation. Clin Microbiol Infect 2002, 8(12):823-825.

5. Jacoby GA: AmpC beta-lactamases. Clinical microbiology reviews 2009, 22(1):161-182. Table of Contents.

6. Livermore DM, Brown DF, Quinn JP, Carmeli Y, Paterson DL, Yu VL: Should third-generation cephalosporins be avoided against AmpC-inducible Enterobacteriaceae? Clin Microbiol Infect 2004, 10(1):84-85.

7. Sanders WE Jr, Sanders CC: Inducible beta-lactamases: clinical and epidemiologic implications for use of newer cephalosporins. Rev Infect Dis 1988, 10(4):830-838.

8. Clinical and Laboratory Standards Institute: Performance Standards for Antimicrobial Susceptibility Testing; Twentieth Informational Supplement M100-S20. Wayne, PA: Clinical and Laboratory Standards Institute; 2010.

9. Kumar A, Roberts D, Wood KE, Light B, Parrillo JE, Sharma S, Suppes R, Feinstein D, Zanotti S, Taiberg L, Gurka D, Kumar A, Cheang M: Duration of hypotension before initiation of effective antimicrobial therapy is the critical determinant of survival in human septic shock. Crit Care Med 2006, 34(6):1589-1596.

10. Chow JW, Fine MJ, Shlaes DM, Quinn JP, Hooper DC, Johnson MP, Ramphal R, Wagener MM, Miyashiro DK, Yu VL: Enterobacter bacteremia: clinical features and emergence of antibiotic resistance during therapy. Ann Intern Med 1991, 115(8):585-590.

11. Kaye KS, Cosgrove S, Harris A, Eliopoulos GM, Carmeli Y: Risk factors for emergence of resistance to broad-spectrum cephalosporins among Enterobacter spp. Antimicrob Agents Chemother 2001, 45(9):2628-2630.

12. Cosgrove SE, Kaye KS, Eliopoulous GM, Carmeli Y: Health and economic outcomes of the emergence of third-generation cephalosporin resistance in Enterobacter species. Arch Intern Med 2002, 162(2):185-190.

13. Choi SH, Lee JE, Park SJ, Choi SH, Lee SO, Jeong JY, Kim MN, Woo JH, Kim YS: Emergence of antibiotic resistance during therapy for infections caused by Enterobacteriaceae producing $\mathrm{AmpC}$ beta-lactamase: implications for antibiotic use. Antimicrob Agents Chemother 2008, 52(3):995-1000.

14. Olson B, Weinstein RA, Nathan C, Kabins SA: Broad-spectrum beta-lactam resistance in Enterobacter: emergence during treatment and mechanisms of resistance. J Antimicrob Chemother 1983, 11(4):299-310.

15. Leal J, Gregson DB, Ross T, Flemons WW, Church DL, Laupland KB: Development of a novel electronic surveillance system for monitoring of bloodstream infections. Infect Control Hosp Epidemiol 2010, 31(7):740-747.

16. Quan H, Sundararajan V, Halfon P, Fong A, Burnand B, Luthi JC, Saunders LD, Beck CA, Feasby TE, Ghali WA: Coding algorithms for defining comorbidities in ICD-9-CM and ICD-10 administrative data. Med Care 2005, 43(11):1130-1139.

17. Sundararajan V, Quan H, Halfon P, Fushimi K, Luthi JC, Burnand B, Ghali WA, International Methodology Consortium for Coded Health I: Cross-national comparative performance of three versions of the ICD-10 Charlson index. Med Care 2007, 45(12):1210-1215.

18. Laupland KB, Gregson DB, Church DL, Ross T, Pitout JD: Incidence, risk factors and outcomes of Escherichia coli bloodstream infections in a large Canadian region. Clin Microbiol Infect 2008, 14(11):1041-1047.

19. Pitout JD, Le PG, Moore KL, Church DL, Gregson DB: Detection of AmpC beta-lactamases in Escherichia coli, Klebsiella spp., Salmonella spp. and Proteus mirabilis in a regional clinical microbiology laboratory. Clin Microbiol Infect 2010, 16(2):165-170. 
20. Pfaller MA, Jones RN, Marshall SA, Coffman SL, Hollis RJ, Edmond MB, Wenzel RP: Inducible amp C beta-lactamase producing gram-negative bacilli from blood stream infections: frequency, antimicrobial susceptibility, and molecular epidemiology in a national surveillance program (SCOPE). Diagn Microbiol Infect Dis 1997, 28(4):211-219.

21. Kim BN, Lee SO, Choi SH, Kim NJ, Woo JH, Ryu J, Kim YS: Outcome of antibiotic therapy for third-generation cephalosporin-resistant Gram-negative bacteraemia: an analysis of 249 cases caused by Citrobacter, Enterobacter and Serratia species. Int J Antimicrob Agents 2003, 22(2):106-111.

22. Deal EN, Micek ST, Ritchie DJ, Reichley RM, Dunne WM Jr, Kollef MH: Predictors of in-hospital mortality for bloodstream infections caused by Enterobacter species or Citrobacter freundii. Pharmacotherapy 2007, 27(2):191-199.

23. Cheong HS, Ko KS, Kang Cl, Chung DR, Peck KR, Song JH: Clinical significance of infections caused by extended-spectrum beta-lactamase-producing Enterobacteriaceae blood isolates with inducible AmpC beta-lactamase. Microb Drug Resist 2012, 18(4):446-452.

24. Choi SH, Kim YS, Chung JW, Kim TH, Choo EJ, Kim MN, Kim BN, Kim NJ, Woo JH, Ryu J: Serratia bacteremia in a large university hospital: trends in antibiotic resistance during 10 years and implications for antibiotic use. Infect Control Hosp Epidemiol 2002, 23(12):740-747.

25. Kang Cl, Kim SH, Park WB, Lee KD, Kim HB, Oh MD, Kim EC, Choe KW: Bloodstream infections caused by Enterobacter species: predictors of 30-day mortality rate and impact of broad-spectrum cephalosporin resistance on outcome. Clin Infect Dis 2004, 39(6):812-818.

26. Lee IK, Liu JW: Clinical characteristics and risk factors for mortality in Morganella morganii bacteremia. J Microbiol Immunol Infect 2006, 39(4):328-334

27. Lin YC, Chen TL, Ju HL, Chen HS, Wang FD, Yu KW, Liu CY: Clinical characteristics and risk factors for attributable mortality in Enterobacter cloacae bacteremia. J Microbiol Immunol Infect 2006, 39(1):67-72.

28. Liu CP, Wang NY, Lee CM, Weng LC, Tseng HK, Liu CW, Chiang CS, Huang FY: Nosocomial and community-acquired Enterobacter cloacae bloodstream infection: risk factors for and prevalence of SHV-12 in multiresistant isolates in a medical centre. J Hosp Infect 2004, 58(1):63-77.

29. Shih HI, Lee HC, Lee NY, Chang CM, Wu CJ, Wang LR, Ko NY, Ko WC: Serratia marcescens bacteremia at a medical center in southern Taiwan: high prevalence of cefotaxime resistance. J Microbiol Immunol Infect 2005, 38(5):350-357.

30. Laupland KB, Gregson DB, Zygun DA, Doig CJ, Mortis G, Church DL: Severe bloodstream infections: a population-based assessment. Crit Care Med 2004, 32(4):992-997.

31. Lodise TP, McKinnon PS, Swiderski L, Rybak MJ: Outcomes analysis of delayed antibiotic treatment for hospital-acquired Staphylococcus aureus bacteremia. Clin Infect Dis 2003, 36(11):1418-1423.

32. Schramm GE, Johnson JA, Doherty JA, Micek ST, Kollef MH: Methicillinresistant staphylococcus aureus sterile-site infection: the importance of appropriate initial antimicrobial treatment. Crit Care Med 2006, 34(8):2069-2074

33. Kim SH, Park WB, Lee KD, Kang Cl, Bang JW, Kim HB, Kim EC, Oh MD, Choe KW: Outcome of inappropriate initial antimicrobial treatment in patients with methicillin-resistant Staphylococcus aureus bacteraemia. J Antimicrob Chemother 2004, 54(2):489-497.

34. Laupland KB, Church DL, Mucenski M, Sutherland LR, Davies HD: Population-based study of the epidemiology of and the risk factors for invasive Staphylococcus aureus infections. J Infect Dis 2003, 187(9):1452-1459.

35. Lin MY, Weinstein RA, Hota B: Delay of active antimicrobial therapy and mortality among patients with bacteremia: impact of severe neutropenia. Antimicrob Agents Chemother 2008, 52(9):3188-3194.

36. Scarsi KK, Feinglass JM, Scheetz MH, Postelnick MJ, Bolon MK, Noskin GA Impact of inactive empiric antimicrobial therapy on inpatient mortality and length of stay. Antimicrob Agents Chemother 2006, 50(10):3355-3360.
37. Tabah A, Koulenti D, Laupland K, Misset B, Valles J, BruzzideCarvalho F, Paiva JA, Cakar N, Ma X, Eggimann P, Antonelli M, Bonten MJ, Csomos A, Krueger WA, Mikstacki A, Lipman J, Depuydt P, Vesin A, Garrouste-Orgeas M, Zahar JR, Blot S, Carlet J, Brun-Buisson C, Martin C, Rello J, Dimopoulos G, Timsit JF: Characteristics and determinants of outcome of hospital-acquired bloodstream infections in intensive care units: the EUROBACT International Cohort Study. Intensive Care Med 2012, 38(12):1930-1945.

\section{Submit your next manuscript to BioMed Central and take full advantage of:}

- Convenient online submission

- Thorough peer review

- No space constraints or color figure charges

- Immediate publication on acceptance

- Inclusion in PubMed, CAS, Scopus and Google Scholar

- Research which is freely available for redistribution

Submit your manuscript at www.biomedcentral.com/submit
() Biomed Central 